\title{
Effects of Adrenomedullin on the Glomerular Adrenomedullin System in a Rat Model of Anti-Thy1 Glomerulonephritis
}

\author{
Bettina Geissler ${ }^{a} \quad$ Christian Plank $^{a} \quad$ Andrea Hartner $^{\mathrm{a}}$ Kerstin Amann ${ }^{\mathrm{c}}$ \\ Friedrich G. Struwe ${ }^{a} \quad$ Karl F. Hilgers ${ }^{b}$ Wolfgang Rascher ${ }^{a} \quad$ Jörg Dötsch ${ }^{d}$ \\ ${ }^{a}$ Kinder- und Jugendklinik, ${ }^{b}$ Medizinische Klinik 4, and ${ }^{~ C I n s t i t u t ~ f u ̈ r ~ P a t h o l o g i e ~ U n i v e r s i t a ̈ t s k l i n i k u m ~ E r l a n g e n, ~}$ \\ Erlangen, and ${ }^{d}$ Klinik und Poliklinik für Allgemeine Kinderheilkunde, Uniklinik Köln, Köln, Germany
}

\section{Key Words}

Adrenomedullin • Anti-Thy1 glomerulonephritis •

Glomerular sieving • Laser-assisted microdissection

\begin{abstract}
Background: Adrenomedullin (ADM) has antiproliferative effects on glomerular mesangial cells. The study was performed to determine changes in glomerular gene expression of the ADM system by ADM treatment in anti-Thy1 glomerulonephritis (GN). Methods: GN in rats was induced by injecting anti-Thy-1 antibody. To show the effect of ADM treatment, rats received ADM from day 3 to day 6 of GN. Supplemental rats were sacrificed on day 3, 7 and 14 of GN to show the expression pattern of adrenomedullin and its receptors. Glomeruli were prepared by sieving or laser-assisted microdissection. Expression of ADM, calcitonin receptor-like receptor (CLR), receptor activity-modifying proteins (RAMP) 1-3, CD34, Thy1 and nephrin was analyzed using real-time PCR. Results: During GN a reduction of CLR and RAMP $2+3$ expressions was detected on days 3, 7 and 14, while RAMP 1 rose. ADM mRNA decreased on days 3 and 7. Thy 1 expression as a surrogate of mesangial cell number was downregulated during GN. A significant reduction of CD34 expression, as a surrogate for endothelial cell number, was detected on day 7. A tendency towards reduction of nephrin gene expression,
\end{abstract}

as a surrogate for number of podocytes, was seen. The administration of ADM during GN did not change the expression on Thy1, CD34 or nephrin. The results were similar for microdissected and sieved glomeruli. In ADM-treated GN animals ADM gene expression rose compared to untreated GN animals on day 6 . These effects were detected both in sieved and microdissected glomeruli. ADM administration did not change the expression of the receptors. Conclusion: The downregulation of adrenomedullin during $\mathrm{GN}$ at the gene level can be improved by ADM application.

Copyright $\odot 2010$ S. Karger AG, Basel

\section{Introduction}

Adrenomedullin (ADM), a 52 amino acid peptide originally isolated from human phaeochromocytoma, is a potent vasodilator and is expressed in various organs throughout the body where it exerts systemic and local effects $[1,2]$. In the kidney, ADM is produced in glomerular endothelial cells, vascular smooth muscle cells, distal and collecting tubules and mesangial cells [1]. In most cell types, ADM acts via a G-protein-coupled receptor

Bettina Geissler and Christian Plank contributed equally to this study.

\section{KARGER}

Fax +4161306 1234 E-Mail karger@karger.ch www.karger.com
(C) 2010 S. Karger AG, Base

$1660-2129 / 10 / 1153-0080 \$ 26.00 / 0$

Accessible online at:

www.karger.com/nee
Jörg Dötsch, MD

Klinik und Poliklinik für Allgemeine Kinderheilkunde

Kerpener Strasse 62

DE-50937 Köln (Germany)

Tel. +49 221478 4359, Fax +49 221478 4635, E-Mail joerg.doetsch@uk-koeln.de 
named calcitonin receptor-like receptor (CLR). Receptor activity-modifying proteins (RAMP) 2 and 3 that are coupled to CLR determine whether the receptor acts as an ADM1 or an ADM2 receptor [3]. Glomerular endothelial cells predominantly express RAMP 2 and CLR [4], while mesangial cells mainly express RAMP 3 and CRL [5]. Podocytes express RAMP 2, RAMP 3 and CLR [6]. In contrast, calcitonin gene-related peptide (CGRP) acts via the CLR modified by RAMP 1 [3].

In vitro, ADM relaxes mesangial cells via cAMP. It also reduces the generation of reactive oxygen species by mesangial cells [7] and inhibits angiotensin II induced migration and proliferation of mesangial cells [8]. Furthermore, a dose-dependent antiproliferative effect of $\mathrm{ADM}$ on mesangial cells was shown in vitro $[8,9]$. In addition, we could recently show that ADM application to rats with experimental mesangioproliferative glomerulonephritis (anti-Thyl-glomerulonephritis, GN), induced by application of a Thyl antibody, reduced mesangial cell proliferation, increased apoptosis, lowered glomerular monocyte infiltration, and reduced inflammation in vivo as well [10]. What role the ADM system plays in mesangioproliferative glomerulonephritis is still unclear. Because of the increased number of mesangial cells, both a reduced or unaltered ADM system during GN are possible. Because of the antiproliferative effect of ADM, it is interesting to what extent the administration of $\mathrm{ADM}$ during GN affects the endogenous ADM system.

Therefore, we tested the hypothesis whether experimental mesangioproliferative GN is accompanied by lower gene expression of ADM, CLR, and RAMP $2+3$. Second, we hypothesized that by administering ADM into rats in a nonhypotensive dose 3 days after the induction of acute anti-Thyl-GN, ADM expression can be restored. Since the main aspect of GN is mesangial cell proliferation, we focused expression analysis on the glomerular changes of components of the ADM system. There are different methods of investigating changes in the gene expression of the glomerular ADM system. Both laserassisted glomerular microdissection and glomerular sieving have been used to determine glomerular gene expression $[11,12]$. We tested whether laser-assisted glomerular microdissection and glomerular sieving of the glomeruli are equally reliable methods of harvesting glomeruli for the detection of changes in ADM gene expression.

Furthermore, we quantified the number of mesangial cells, podocytes and endothelial cells during GN and under ADM treatment by measuring Thyl, nephrin and CD34 as surrogates of cell quantity.

Adrenomedullin in Anti-Thyl

Glomerulonephritis

\section{Methods}

Experimental Disease and Adrenomedullin Treatment

Male Sprague-Dawley rats (170-200 g) were obtained from Charles River Deutschland (Sulzfeld, Germany). Rats were housed in a room maintained at $22 \pm 2{ }^{\circ} \mathrm{C}$, exposed to a 12-hour dark/ light cycle. The animals were allowed unlimited access to standard chow (\# 1320, Altromin, Lage, Germany) and tap water. All procedures performed on animals were done in accordance with guidelines of the American Physiological Society and were approved by the local government authorities (Regierung von Mittelfranken, AZ \# 621-2531.31-11/02).

GN was induced by a single intravenous injection of $1 \mathrm{mg} / \mathrm{kg}$ body weight monoclonal anti-Thyl antibody (ER4, Antibody Solutions, Palo Alto, Calif., USA) into the tail vein in light ether anesthesia. In this model, the monoclonal antibody against the Thyl antigen on rat mesangial cells induces acute complement-mediated mesangiolysis, followed by mesangial proliferation and glomerular repair over a period of 3 weeks [13]. Control animals were injected isotonic saline. To examine sequential changes in the mRNA expression of ADM and its receptor system during GN, a proportion of animals remained without further treatment and were sacrificed on day 3 (Thyl day $3, \mathrm{n}=8$ ), 7 (Thyl day $7, \mathrm{n}=8$ ) and 14 (Thyl day 14, n =7) after induction of GN. Control animals (control, $\mathrm{n}=8$ ) were animals of the same age, without injection of the antibody. To analyze the effect of exogenous ADM Application, another group of GN animals received osmotic minipumps (Alzet model 2001; Alza Scientific Products, Palo Alto, Calif., USA) subcutaneously on day 3 after induction of GN. The pumps continuously delivered recombinant rat ADM (H5694, Bachem AG, Weil am Rhein, Germany) $500 \mathrm{ng} / \mathrm{h}$, or vehicle (aqua injectable; VEH) from day 3 to day 6 of disease. The rats were divided into 4 groups: nephritic rats with ADM treatment (GN+ADM; $\mathrm{n}=11)$, nephritic rats treated with VEH $(\mathrm{GN}+\mathrm{VEH} ; \mathrm{n}=12)$, control animals with ADM treatment $(\mathrm{CO}+\mathrm{ADM} ; \mathrm{n}=5)$, and control animals treated with $\mathrm{VEH}(\mathrm{GN}+\mathrm{VEH}, \mathrm{n}=5)$.

Rats were sacrificed and the kidneys were decapsulated. Portions of the kidney were immediately snap-frozen in liquid nitrogen for mRNA analysis. One half of the kidney was immersed in Tissue-Tec ${ }^{\circledR}$ (Sakura Finetek, Zoeterwoude, The Netherlands) and immediately snap-frozen in liquid nitrogen for microdissection. Another portion of renal tissue was fixed in Methyl-Carnoy solution $(60 \%$ methanol, $30 \%$ chloroform and $10 \%$ glacial acetic acid). The other kidney was used to isolate glomeruli by a sieving technique at $4^{\circ} \mathrm{C}$.

\section{RNA Extraction}

The effects of mesangioproliferative GN are localized in the glomerulus. Therefore it is essential to examine glomeruli and not only homogenized tissue. Because it is unclear what isolation method is the better one, we used and compared sieving of glomeruli and laser-captured microdissection (LCM). For the sieving procedure, we used the whole kidney which was cut into pieces. Glomeruli were isolated by sequentially pressing the kidney tissue through 180, 125 and $75 \mu \mathrm{m}$ sieves at a temperature of $4^{\circ} \mathrm{C}$. Each sieve was thoroughly washed with ice-cold PBS buffer. Tissue samples containing glomeruli were finally collected from the 75$\mu \mathrm{m}$ sieve [13-16].

For the microdissection procedure, we used one half of the kidney, which had been immersed in Tissue-Tec (Sakura Finetek, 
Table 1. Details of primers and TaqMan probes used in this study

\begin{tabular}{|c|c|c|}
\hline $\mathrm{ADM}$ & $\begin{array}{l}\text { forward } \\
\text { reverse } \\
\text { probe }\end{array}$ & $\begin{array}{l}\text { 5'-CTCAGAGCACAGCCCACATTC-3' } \\
\text { 5'-GCATTGTGCAGGTCCCAAAG-3' } \\
\text { 5'(FAM)-ACCGCCAGAGCATGAACCAGGG-(TAMRA) 3' }\end{array}$ \\
\hline CLR & $\begin{array}{l}\text { forward } \\
\text { reverse } \\
\text { probe }\end{array}$ & $\begin{array}{l}\text { 5'-CCATCGCCAGAAGCTTGTATTAC-3' } \\
\text { 5'-TGGGACCATGGATGATGTAGAG-3' } \\
\text { 5'(FAM)-ATGACAACTGCTGGATCAGCTCAGACAC-(TAMRA) 3' }\end{array}$ \\
\hline RAMP-1 & $\begin{array}{l}\text { forward } \\
\text { reverse } \\
\text { probe }\end{array}$ & $\begin{array}{l}\text { 5'-GGAAGACTCTGTGGTGTGACTGG-3' } \\
\text { 5'-TCTTGTTTGCCACGAGTTTGG-3' } \\
\text { 5'(FAM)-AGACCATAGGGAGCTATGGGGAGCTCACT-(TAMRA)3' }\end{array}$ \\
\hline RAMP-2 & $\begin{array}{l}\text { forward } \\
\text { reverse } \\
\text { probe }\end{array}$ & $\begin{array}{l}\text { 5'-GACTCTGTCAAGGACTGGTGCAACT-3' } \\
\text { 5'-CAGTTGGCAAAGTGTATCAGGTGAGC-3' } \\
\text { 5'(FAM)-ACTTTGATTAGCAGGTATTACAGCAACCTGCGG-(TAMRA)3' }\end{array}$ \\
\hline RAMP-3 & $\begin{array}{l}\text { forward } \\
\text { reverse } \\
\text { probe }\end{array}$ & $\begin{array}{l}\text { 5'-AGAAGGTGGACGTCTGGAAGTG-3' } \\
\text { 5'-TCCGTGCAGTTAGTGAAGCTTTC-3' } \\
\text { 5'(FAM)-TGCAACCTGTCGGAGTTCATCGTGTACT-(TAMRA)3' }\end{array}$ \\
\hline Thy1 & $\begin{array}{l}\text { forward } \\
\text { reverse } \\
\text { probe }\end{array}$ & $\begin{array}{l}\text { 5'-AACCCAGTCATCAGCATCACTCT-3' } \\
\text { 5'-TTCACCAGGCAGGCTGTCA-3' } \\
\text { 5'(FAM)-CTGCTTTCAGTCTTGCAGATGTCCCGA-(TAMRA) 3' }\end{array}$ \\
\hline Nephrin & $\begin{array}{l}\text { forward } \\
\text { reverse } \\
\text { probe }\end{array}$ & $\begin{array}{l}\text { 5'-CGTGCTAAAGGCGAGTTCCA-3' } \\
\text { 5'-GGAGAGGATTACTTTAGGAGACACAAG-3' } \\
\text { 5'(FAM)-TATGAATGCCAAGTCGGCCGCTCA-(TAMRA) 3' }\end{array}$ \\
\hline CD34 & $\begin{array}{l}\text { forward } \\
\text { reverse } \\
\text { probe }\end{array}$ & $\begin{array}{l}\text { 5'-TCTCAGAGACCACGGTCAACTTTA-3' } \\
\text { 5'-GGTAAGTCTGTGGTTGTGAAAAAGTG-3' } \\
\text { 5'(FAM)-CTGGGACCCCTTCAGGCTCTGGAA-(TAMRA) 3' }\end{array}$ \\
\hline$\beta$-Actin & $\begin{array}{l}\text { forward } \\
\text { reverse } \\
\text { probe }\end{array}$ & $\begin{array}{l}\text { 5'-TGAGCTGCCTGACGGTCAG-3' } \\
\text { 5'-TGCCACAGGATTCCATACCC-3' } \\
\text { 5'(FAM)-CACTATCGGCAATGAGCGGTTCCG-(TAMRA)3' }\end{array}$ \\
\hline GAPDH & $\begin{array}{l}\text { forward } \\
\text { reverse } \\
\text { probe }\end{array}$ & $\begin{array}{l}\text { 5'-ACGGGAAACCCATCACCAT-3' } \\
\text { 5'-CCAGCATCACCCCATTTGA-3' } \\
\text { 5'(FAM)-TTCCAGGAGCGAGATCCCGTCAAG-(TAMRA)3' }\end{array}$ \\
\hline
\end{tabular}

Zoeterwoude, The Netherlands) and immediately snap-frozen in liquid nitrogen. Frozen tissues were cut into $10-\mu \mathrm{m}$-thick full size cross-sections with a cryostat. Sections were placed onto MMI MembraneSlides provided with a $2-\mu \mathrm{m}$-thick, clear polyethylene membrane (MMI AG, Glattbrugg, Switzerland). $\mu$ Cut Laser Microdissection system (MMI AG) was set to the following parameters: laser wavelength $337 \mathrm{~nm}$, laser spot diameter $30 \mu \mathrm{m}$ [11]. LCM was performed on 20 glomeruli from each rat in GN on day 3,7 and 14. Glomeruli of control animals served as control. The glomeruli were dissected from adjacent tissue at $\times 200$ magnification. They were isolated from the glass slides by adhesion to the tip of a micro fine needle $(0.25 \times 8 \mathrm{~mm}$, Becton Dickinson, Heidelberg, Germany), and were transferred into a reaction tube on RNAse-free conditions. For RNA extraction of homogenized total renal cortex we used tissue immediately snap-frozen.

RNA was extracted from isolated glomeruli and total renal cortex using TRIzol reagent (Invitrogen, Paisley, UK) according to the manufacturer's instructions. The RNA from microdissect- ed glomeruli was isolated using a lysis buffer containing RTbuffer, DTT (Invitrogen) an RNAse inhibitor (Roche, Mannheim, Germany) as well as Proteinase K (Roche).

\section{Real-Time PCR}

Quantitative real-time RT-PCR analysis was performed as described previously [17] for ADM, CLR, RAMP 1-3, Thyl, nephrin and CD34. In microdissected glomeruli the PCR was performed under the same conditions, however over 55 cycles considering the lower RNA concentration. The relative amount of specific mRNA was normalized to $\beta$-actin and glyceraldehyde-3-phosphate dehydrogenase (GAPDH), respectively. Oligonucleotides for each gene investigated were designed with Primer Express software (Perkin-Elmer, Foster City, Calif., USA) using uniform selection parameters allowing for the application of standard cycle conditions. Details on primers and TaqMan probes used are listed in table 1. 

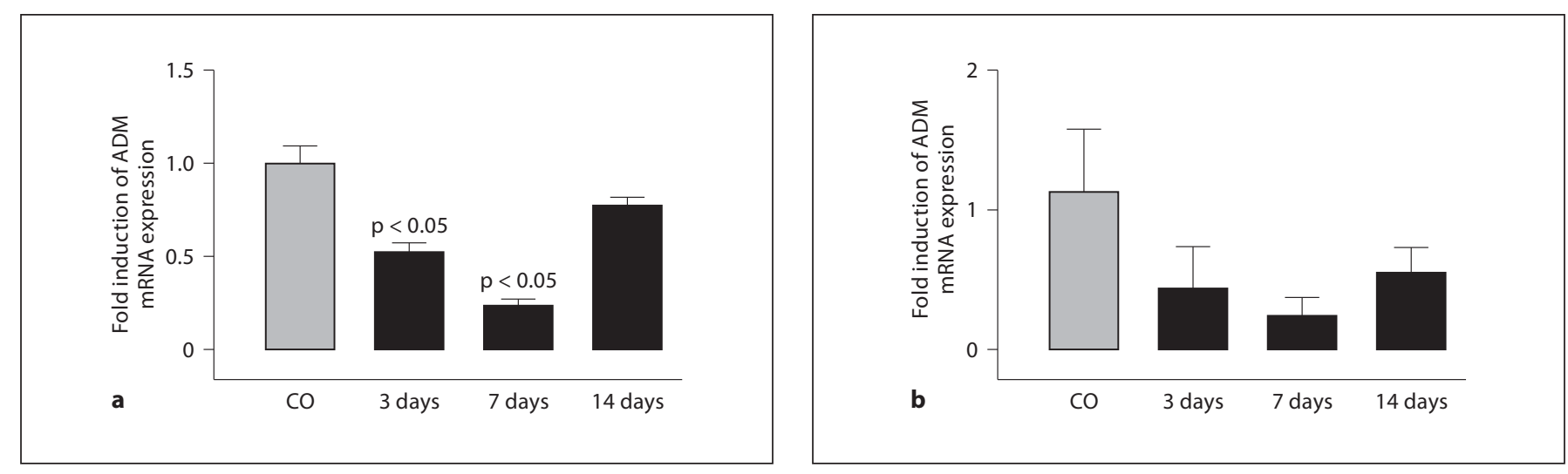

Fig. 1. ADM gene expression in glomeruli of Sprague-Dawley rats as a function of anti-Thyl-GN induction. Values are shown as mean \pm SEM of three samples in $\mathbf{a}$ and $7-8$ samples in $\mathbf{b}$. Significant results are shown in comparison to controls (CO). Expression is normalized to $\beta$-actin. a ADM expression in sieved glomeruli. b ADM expression in glomeruli obtained by laser-assisted microdissection.

\section{Analysis of Data}

The results of RT-PCR were calculated related to an internal standard and are given as induction of mRNA expression compared to mean expression level in VEH-treated CO animals or CO animals. This expression was defined as 1.0 -fold induction. Oneway analysis of variance followed by post-hoc Bonferroni test with adjustment for multiple comparisons was used to test significance of differences between groups. $\mathrm{p}<0.05$ was considered significant. Additionally, a one-tailed t test was performed to compare ADM-treated GN animals to nontreated GN animals. The procedures were carried out using the Graph Pad Prism software (Version 3, GraphPad Software, San Diego, Calif., USA). Values are displayed as means \pm SEM.

\section{Results}

In sieved glomeruli of male Sprague-Dawley rats, ADM gene expression, normalized to $\beta$-actin, was significantly reduced on days 3 and 7 after induction of GN and regained almost normal values on day 14 after onset of the disease (fig. 1a). Similar results were obtained when normalizing ADM expression to the house-keeping gene GAPDH (data not shown). Laser-captured microdissection of glomeruli yielded a reduction of ADM gene expression as well when normalized to $\beta$-actin (fig. $1 b$ ) and GAPDH. However, with microdissection of only a limited number of glomeruli, statistical testing did not obtain significant results. Because of the similar results gained by sieving or microdissection, we used only sieved glomeruli for further experiments.

In sieved glomeruli gene expression of Thyl, being a surrogate of mesangial cell number, normalized to $\beta$-ac- tin, was significantly reduced on day 3 of GN. In the course of GN, expression increased again (fig. 2). There was a tendency towards a reduction of nephrin gene expression, as a marker for number of podocytes on day 7 of GN, not reaching statistical significance (fig. 3). Furthermore, we found a significant reduction of CD34 gene expression, as a surrogate of endothelial cell number, normalized to $\beta$-actin on day 7 (fig. 4). Similar results were obtained by normalizing gene expression to GAPDH (data not shown).

Under subcutaneous application of ADM, starting on day 3 of $\mathrm{GN}$, the difference in $\mathrm{ADM}$ gene expression that was seen between VEH-treated CO and GN animals on day 6 of GN was reduced (fig. 5). While we found a reduction of ADM gene expression to 0.16 -fold in nephritic rats, glomeruli of ADM-treated nephritic rats only showed a 0.4 -fold value compared to pretreatment. This difference was statistically significant. Similar results were seen when ADM was normalized to GAPDH (data not shown).

Gene expressions of the different components of the ADM receptor, i.e. CLR and the RAMP 2 and 3 in sieved glomeruli were significantly reduced. But the expression of CLR, RAMP 2, and RAMP 3 did not return to control levels 14 days after the induction of GN. Details are shown in figure 6. Similar results were obtained for the normalization of gene expression to GAPDH (data not shown).

RAMP-1 gene expression in sieved glomeruli of rats with GN, normalized to $\beta$-actin, did not decrease, but increased significantly on day 3 and 14 just falling short of being significant on day 7 (fig. 6). Similar results were 


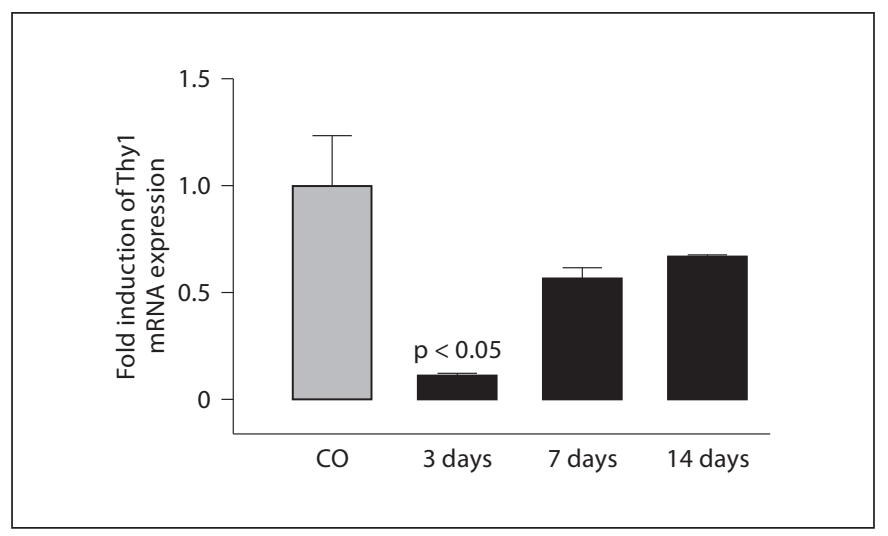

Fig. 2. Thyl gene expression in sieved glomeruli of Sprague-Dawley rats as a function of anti-Thyl-GN induction. Expression is normalized to $\beta$-actin. Values are shown as mean \pm SEM of three samples. Results are shown in comparison to controls (CO).

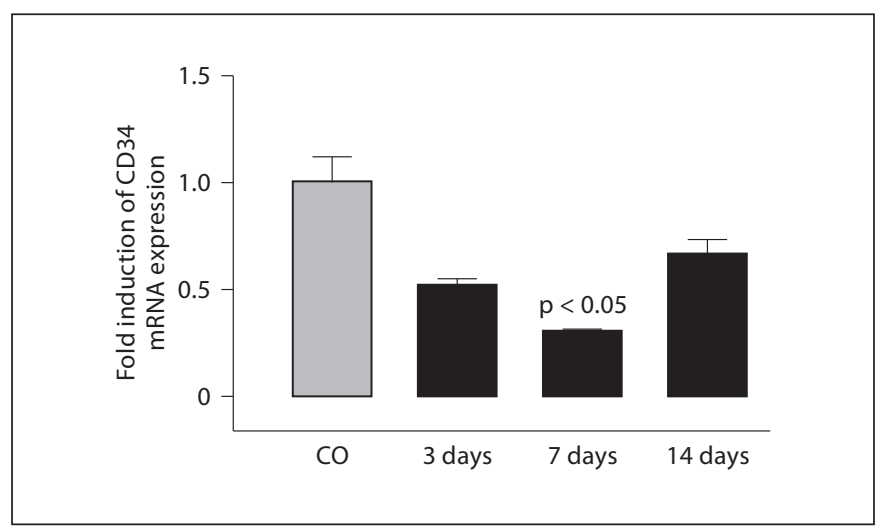

Fig. 4. CD34 gene expression in sieved glomeruli of SpragueDawley rats as a function of anti-Thyl-GN induction. Expression is normalized to $\beta$-actin. Values are shown as mean \pm SEM of three samples. Results are shown in comparison with controls (CO).

obtained for the normalization of RAMP 1 to GAPDH (data not shown).

Unlike the changes in ADM expression, the expression of the receptor system could not be influenced by subcutaneous ADM treatment. Neither in sieved nor in microdissected glomeruli could we find any significant changes (fig. 7). The expression of CD34, nephrin and Thyl normalized to $\beta$-actin, as a surrogate of cell quantity of different cell types in the glomerulus did not reveal significant differences in the ADM-treated GN group.

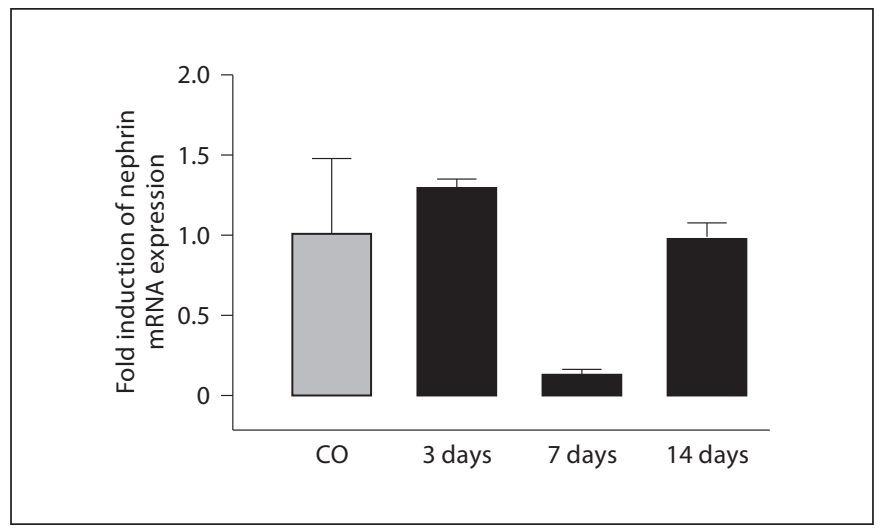

Fig. 3. Nephrin gene expression in sieved glomeruli of SpragueDawley rats as a function of anti-Thy1-GN induction. Expression is normalized to $\beta$-actin. Values are shown as mean \pm SEM of three samples. Results are shown in comparison to controls (CO).

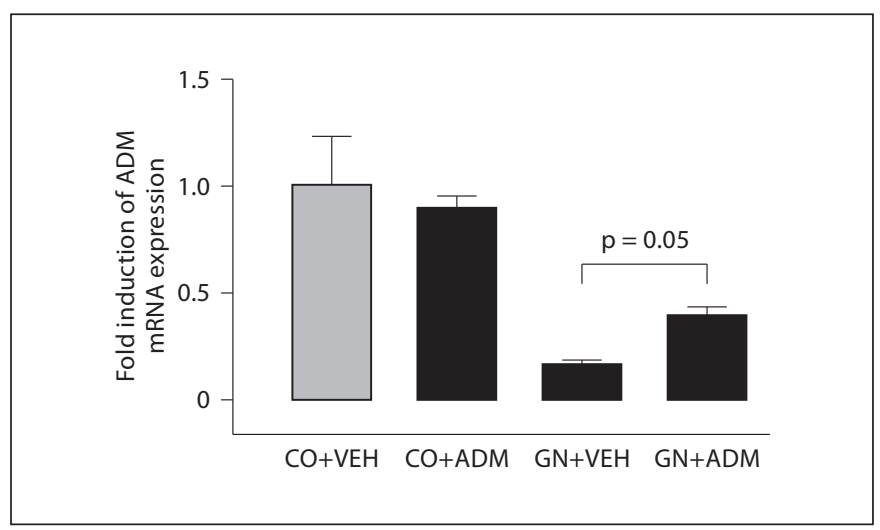

Fig. 5. ADM expression in sieved glomeruli of Sprague-Dawley rats with anti-Thyl-GN during subcutaneous ADM treatment. The significant reduction of $\mathrm{ADM} / \beta$-actin expression between VEH-treated control (CO) animals and VEH-treated rats with Anti-Thyl-nephritis is not present in ADM-treated animals. Values are shown as mean \pm SEM of three samples.

CD34 gene expression showed 2.83-fold induction in ADM-treated nephritic rats compared to control animals, while untreated nephritic animals show a 1.93 -fold value. Expression of Thyl showed a 2.36 -fold value in ADM-treated animals compared to a 1.81 -fold value in untreated nephritic rats. Glomeruli of ADM-treated nephritic rats only showed a 0.84 -fold value in nephrin expression. Gene expression of nephrin was almost equal in the untreated GN group with a value of 0.85 . The results were similar when normalized to GAPDH. 
Fig. 6. Gene expression of CLR and the RAMP 2 and 3 in sieved glomeruli as a function of time after induction of antiThy1-GN. Expression is normalized to $\beta$ actin. Similar results were obtained for normalization to GAPDH. Values are shown as mean \pm SEM of three samples. $p$ values are given in comparison to control values.

Fig. 7. Gene expression of CLR and the RAMP 2 and 3 in sieved glomeruli during subcutaneous ADM treatment on day 6 of GN. Expression is normalized to $\beta$-actin. Statistical analysis was performed: (1) $\mathrm{GN}+\mathrm{ADM}$ vs. GN+VEH, (2) GN+VEH vs. $\mathrm{CO}+\mathrm{VEH}$, and (3) $\mathrm{CO}+\mathrm{ADM}$ vs. $\mathrm{CO}+\mathrm{VEH}$. Similar results were obtained for normalization to GAPDH. Values are shown as mean \pm SEM of 3 samples.

Fig. 8. ADM expression in homogenized renal cortex of Sprague-Dawley rats with anti-Thyl-GN during subcutaneous ADM treatment. The differences shown in sieved glomeruli are not present in homogenized renal cortex. Expression is normalized to $\beta$-actin. Values are shown as mean \pm SEM of 4-7 samples.

Adrenomedullin in Anti-Thyl Glomerulonephritis
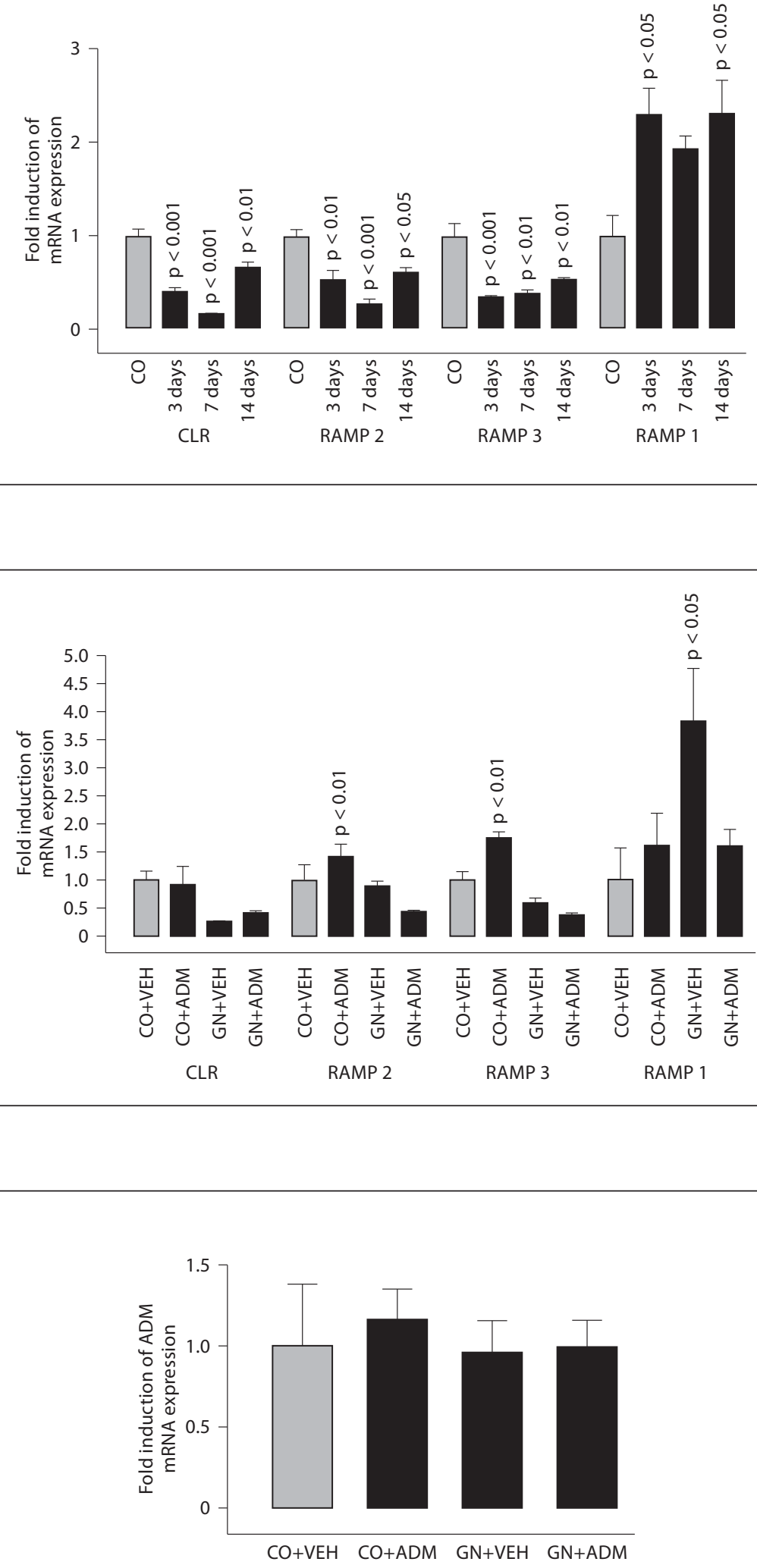

Nephron Exp Nephrol 2010;115:e80-e88 
Fig. 9. Gene expression of CLR and RAMP 2 and 3 in homogenized renal cortex during subcutaneous ADM treatment on day 6 of GN. Expression is normalized to $\beta$ actin. Statistical analysis was performed: $\mathrm{GN}+\mathrm{ADM}$ vs. $\mathrm{GN}+\mathrm{VEH}, \mathrm{GN}+\mathrm{VEH}$ vs. $\mathrm{CO}+\mathrm{VEH}$, and $\mathrm{CO}+\mathrm{ADM}$ vs. $\mathrm{CO}+\mathrm{VEH}$. Similar results were obtained for normalization to GAPDH. Values are shown as mean \pm SEM of 4-7 samples.

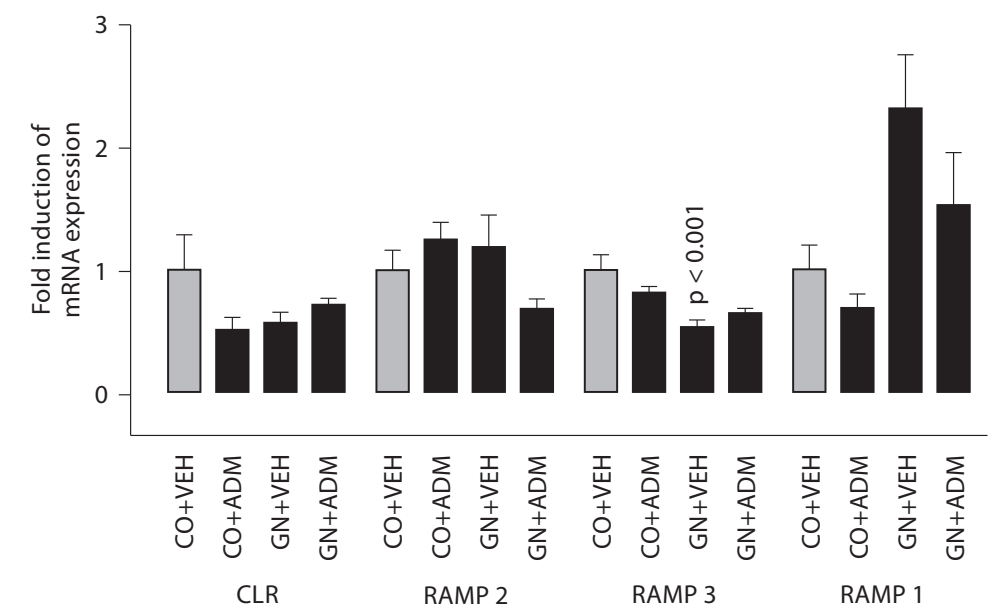

ADM has been proven to inhibit mesangial cell proliferation both in vitro and in vivo [7, 9, 10, 18-21]. As we detected, the reduced activity of the ADM system during the acute phase of GN is one aspect of the process. The question was, whether the external application of subcutaneous ADM is capable not only of blunting the inflammatory process of acute anti-Thyl-GN [10] but also of attenuating the suppression of ADM. This could be shown in the present experiment. ADM application mitigated this effect considerably and increased the glomerular ADM gene expression. ADM application had no effect on the receptor system. The beneficial effect of ADM on renal function has been shown in different settings. Mori et al. [22] demonstrated renoprotective effects of long term subcutaneous infusion of human ADM into hypertensive rats. Chronic ADM infusion reduced glomerular sclerosis without reducing blood pressure in hypertensive rats $[22,23]$.

Despite the fact that the reduction of components of the ADM systems is consistent with previous data on the role of ADM in mesangial cell proliferation, several aspects and limitations have to be discussed.

First, it can be argued that the data on mRNA expression of the components of the ADM system shown in the manuscript might not reflect protein levels. Although this argument cannot completely be disproven, a number of publications suggest that ADM gene expression and protein level go in line in the context of experimental and human mesangioproliferative glomerulonephritis $[15$, 24]. Kuo et al. [24] showed a significant correlation between ADM mRNA expression and ADM protein levels 
in glomeruli in human IgA nephritis. In rat GN Matsumoto et al. [15] showed correlating mRNA and protein levels as well.

However, Matsumoto et al. [15] found no reduction in ADM, CLR, RAMP 2 and 3 gene expressions resulting from the induction of anti-Thyl-GN. On days 14, 21 and 28, the RAMP 2, RAMP 3 and CRLR gene expression in sieved glomeruli did increase temporarily . In our experiments on Sprague-Dawley rats, we found a reduction in the ADM system and no increase during the phase of regeneration. These differences might be explained by the different antibodies used for the induction of GN. While Matsumoto et al. [25] used ATS (anti-rat thymocyte sera), we used a monoclonal rat anti-Thyl antibody.

Up to now, an effect of exogenous ADM administration on the ADM expression has not been described. Linscheid et al. [26] analyzed the influence of ADM administration on the ADM expression in adipocytes. No effect could be detected. In contrast, we could show an influence of ADM administration on the endogenous ADM expression in the model of rat mesangioproliferative glomerulonephritis. We found a significantly higher ADM gene expression in ADM-treated nephritic animals compared to nontreated nephritic animals. This suggests that ADM does not only inhibit the proliferation of mesangial cells in vivo by exogenous application, but even leads to a higher ADM expression. The mechanism that causes this effect is unclear. A benefit of ADM administration on the process of GN has already been described [10]. Proliferation of mesangial cells leads to dedifferentiation [27]. The inhibition of mesangial cell proliferation, as reached through administration of ADM, may avoid dedifferentiation of cells and may thus avoid loss of ability to express ADM.

The main spot of GN is the glomerulus. It is unclear whether sieving glomeruli and microdissection lead to the same reproducible results. Therefore, we compared the data of the sieved and the microdissected glomeruli. We discovered the same level of gene expressions in sieved glomeruli and microdissected glomeruli, irrespective of the used housekeeping gene. Furthermore, microdissection showed the same tendency with regard to ADM regulation as glomerular sieving, although microdissection failed to reach statistical significance. The reason is the low RNA amount in microdissected samples. There is only a limited number of transcripts in each sample. This leads to high variance and hence to high standard deviation. Thus, these methods are equal for the evaluation of glomerular changes. By contrast, extraction of homogenized renal cortex did not show similar changes in glo- merular gene expression. Changes in ADM expression and the expressions of components of the receptor system could not be found in the latter. This underlines the importance of selective measurements in glomeruli, irrespective of the method of preparation.

To what extent these results may be transferred to human mesangioproliferative glomerulonephritis may be speculated upon. IgA nephropathy is characterized by mesangial cell proliferation in humans and is the most common primary glomerulonephritis in the world [28]. The role of the ADM system in IgA nephropathy is still unclear. Plasma levels of ADM in patients with IgA nephropathy were higher or unchanged compared to healthy controls [1]. Urinary levels of ADM lessened in all studies on IgA nephropathy, but did not correlate with serum levels [1]. Other authors [29] showed a decreased gene transcription in peripheral blood mononuclear cells in patients with IgA nephropathy. More recently, it could be demonstrated that glomerular synthesis of ADM diminished in human IgA nephropathy [24]. These data are in line with our own data and may reflect a role of ADM in human mesangioproliferative glomerulonephritis.

In conclusion, our study demonstrates that glomerular gene expression of $\mathrm{ADM}$ and its receptors, but not the CGRP receptor (CLR + RAMP 1) are downregulated during GN in Sprague-Dawley rats as measured both in sieved and microdissected glomeruli, but not in homogenized renal cortex. The downregulation of ADM is partly prevented by exogenous ADM application to the animals, but there is no effect on the receptor system.

\section{Acknowledgements}

With support from the Deutsche Forschungsgemeinschaft (Sonderforschungsbereich 423, projects B13 and Z2). The authors thank Monika Klewer, Stefan Söllner, Miriam Reutelshöfer and Jessica Braun for excellent technical assistance.

\section{References}

1 Eto T, Kitamura K: Adrenomedullin and its role in renal diseases. Nephron 2001;89:121134

2 Beltowski J, Jamroz A: Adrenomedullin what do we know 10 years since its discovery? Pol J Pharmacol 2004;56:5-27.

3 Poyner DR, Sexton PM, Marshall I, Smith DM, Quirion R, Born W, Muff R, Fischer JA, Foord SM: International union of pharmacology. Xxxii. The mammalian calcitonin gene-related peptides, adrenomedullin, amylin, and calcitonin receptors. Pharmacol Rev 2002;54:233-246. 
4 Kamitani S, Asakawa M, Shimekake Y, Kuwasako K, Nakahara K, Sakata T: The RAMP2/CRLR complex is a functional adrenomedullin receptor in human endothelial and vascular smooth muscle cells. FEBS Lett 1999; 1:111-114.

5 Nowak W, Parameswaran N, Hall CS, Aiyar N, Sparks HV, Spielman WS: Novel regulation of adrenomedullin receptor by PDGF: role of receptor activity modifying protein-3. Am J Physiol Cell Physiol 2002;6:C1322C1331.

6 Oba S, Hino M, Fujita T: Adrenomedullin protects against oxidative stress-induced podocyte injury as an endogenous antioxidant. Nephrol Dial Transplant 2008;2:510517.

7 Parameswaran N, Nowak W, Hall CS, Sparks $\mathrm{HV}$, Spielman WS: Cellular and molecular actions of adrenomedullin in glomerular mesangial cells. Peptides 2001;22:19191924.

8 Kohno M, Yasunari K, Minami M, Kano H, Maeda K, Mandal AK, Inoki K, Haneda M, Yoshikawa J: Regulation of rat mesangial cell migration by platelet-derived growth factor, angiotensin II, and adrenomedullin. J Am Soc Nephrol 1999;10:2495-2502.

9 Parameswaran N, Nambi P, Brooks DP, Spielman WS: Regulation of glomerular mesangial cell proliferation in culture by adrenomedullin. Eur J Pharmacol 1999;372:8595.

10 Plank C, Hartner A, Klanke B, Geissler B, Porst M, Amann K, Hilgers KF, Rascher W, Dotsch J: Adrenomedullin reduces mesangial cell number and glomerular inflammation in experimental mesangioproliferative glomerulonephritis. Kidney Int 2005;68: 1086-1095.

11 Dimmler A, Haas CS, Cho S, Hattler M, Forster C, Peters H, Schocklmann HO, Amann $\mathrm{K}$ : Laser capture microdissection and realtime PCR for analysis of glomerular endothelin-1 gene expression in mesangiolysis of rat anti-thy 1.1 and murine habu snake venom glomerulonephritis. Diagn Mol Pathol 2003;12:108-117.
12 Porst M, Daniel C, Plank C, Schocklmann $\mathrm{HO}$, Reinhardt DP, Hartner A: Induction and coexpression of latent transforming growth factor beta-binding protein-1 and fibrillin-1 in experimental glomerulonephritis. Nephron Exp Nephrol 2006;102:e99e104.

13 Bagchus WM, Hoedemaeker PJ, Rozing J, Bakker WW: Glomerulonephritis induced by monoclonal anti-thy 1.1 antibodies: a sequential histological and ultrastructural study in the rat. Lab Invest 1986;55:680-687.

14 Rupprecht HD, Dann P, Sukhatme VP, Sterzel RB, Coleman DL: Effect of vasoactive agents on induction of egr-1 in rat mesangial cells: correlation with mitogenicity. Am J Physiol 1992;263:F623-F636.

15 Matsumoto M, Fujimoto S, Iwatsubo S, Sato Y, Hara S, Kitamura K, Eto T: Adrenomedullin (am) and receptor-activity-modifying proteins in glomeruli with thy.1 glomerulonephritis. Clin Exp Nephrol 2004;8:316-321.

16 Hartner A, Hilgers KF, Bitzer M, Veelken R, Schocklmann HO: Dynamic expression patterns of transforming growth factor-beta(2) and transforming growth factor-beta receptors in experimental glomerulonephritis. J Mol Med 2003;81:32-42.

17 Dotsch J, Schoof E, Schocklmann HO, Brune B, Knerr I, Repp R, Rascher W: Nitric oxide increases adrenomedullin receptor function in rat mesangial cells. Kidney Int 2002;61: 1707-1713.

18 Parameswaran N, Nambi P, Hall CS, Brooks DP, Spielman WS: Adrenomedullin decreases extracellular signal-regulated kinase activity through an increase in protein phosphatase-2a activity in mesangial cells. Eur Pharmacol 2000;388:133-138.

19 Segawa K, Minami K, Sata T, Kuroiwa A, Shigematsu A: Inhibitory effect of adrenomedullin on rat mesangial cell mitogenesis. Nephron 1996;74:577-579.

20 Chini EN, Choi E, Grande JP, Burnett JC, Dousa TP: Adrenomedullin suppresses mitogenesis in rat mesangial cells via camp pathway. Biochem Biophys Res Commun 1995;215:868-873.
21 Liu X, Zhang Z, Zhang X, Zhu H, Chen Q, Guo M: The localization of adrenomedullin in rat kidney tissue and its inhibitory effect on the growth of cultured rat mesangial cells. Chin Med Sci J 2002;17:129-133.

22 Mori Y, Nishikimi T, Kobayashi N, Ono H, Kangawa K, Matsuoka H: Long-term adrenomedullin infusion improves survival in malignant hypertensive rats. Hypertension 2002;40:107-113.

23 Nishikimi T, Mori Y, Kobayashi N, Tadokoro K, Wang X, Akimoto K, Yoshihara F, Kangawa K, Matsuoka H: Renoprotective effect of chronic adrenomedullin infusion in dahl salt-sensitive rats. Hypertension 2002;39: 1077-1082.

24 Kuo MC, Kuo HT, Chiu YW, Chang JM, Guh JY, Lai YH, Chen HC: Decreased synthesis of glomerular adrenomedullin in patients with iga nephropathy. J Lab Clin Med 2005;145: 233-238.

25 Sato Y, Fujimoto S, Hamai K, Eto T: Serial alterations of glomerular matrix-degrading metalloproteinase activity in anti-thymocyte-induced glomerulonephritis in rats. Nephron 1998;78:195-200.

26 Linscheid P, Seboek D, Zulewski H, Keller U, Muller B: Autocrine/paracrine role of inflammation-mediated calcitonin gene-related peptide and adrenomedullin expression in human adipose tissue. Endocrinology 2005;146:2699-2708.

27 Ebihara I, Kimura K, Nakamura T, Tomino Y, Yazaki Y, Nagai R, Koide H: Glomerular nonmuscle-type myosin heavy-chain isoform gene expression in glomerulosclerosis. Nephron 1998;79:317-321.

28 Donadio JV, Grande JP: Iga nephropathy. N Engl J Med 2002;347:738-748.

29 Kubo A, Nishitani Y, Minamino N, Kikumoto K, Kurioka H, Nishino T, Iwano M, Shiiki H, Kangawa K, Dohi K: Adrenomedullin gene transcription is decreased in peripheral blood mononuclear cells of patients with IgA nephropathy. Nephron 2000;85:201-206. 